\title{
Endogenous Intermediation in Over-the-Counter Markets
}

\author{
Ana Babus* \\ Imperial College London
}

\begin{abstract}
This paper provides a theory of dynamic intermediation in over-the-counter markets. Intermediation arises so agents that meet infrequently can trade risky assets without collateral. When meeting the same counterparty again is unlikely, an agent develops a long-term relationship with another trader who then acts as an intermediary. In a relationship, two traders condition the terms of trade on information about past transactions. A trade-off exists between forming many relationships and trading through intermediaries. First, maintaining relationships is costly. Second, agents intermediating transactions between others require a fee. I show that in equilibrium one agent intermediates all the trade in the market.
\end{abstract}

Keywords: over-the-counter trading; strategic default; dynamic network formation.

JEL: C70; G21.

\footnotetext{
${ }^{*}$ E-mail: a.babus@imperial.ac.uk.
} 


\section{Introduction}

In over-the-counter markets trade takes place in a decentralized fashion. Parties that wish to trade must search for each other, or trade through an intermediary. As Li and Schurhoff (2011) show, dealers intermediate $94 \%$ of the trades in the municipal bond market, with most of the intermediated trades representing customer-dealer-customer transactions. At the same time, as agents trade bilaterally, they can choose to interact with the same counterparty over time. For instance, Afonso et al. (2011) show that in the Fed Funds market approximately $60 \%$ of the funds an individual bank borrows in one month persistently come from the same lender. These findings raise questions about what is the role of intermediaries and why relationships arise in decentralized markets.

This paper provides a theory of dynamic intermediation in over-the-counter markets. In a market where agents meet sporadically, intermediation arises to allow agents to access more favorable terms of trade than those obtained in one shot interactions. Since the chance of meeting the same counterparty in the future is very small, agents choose to develop long-term relationships with a fixed partner who then acts as an intermediary. Intermediation provides the same aggregate benefits as if agents meet repeatedly. However, since a share of these benefits accrue to the agents that intermediate transactions, trading becomes concentrated. I show that, in equilibrium, one agent intermediates all the trade in the economy.

I consider a dynamic setting where agents trade bilaterally. Some agents have a liquidity surplus and some agents have an investment opportunity. Every period, an agent with a liquidity surplus is randomly paired with an agent with an investment opportunity. The investment opportunity represents a risky asset that offers a high return in the good states of the world and 0 in the bad states of the world. To finance the investment the agent with an investment opportunity borrows cash from the agent with a liquidity surplus. In exchange, he offers a contract that specifies a repayment to be received at the end of the period. The transaction can take place without or against collateral. Since there are limited enforcement problems and an agent with an investment opportunity may be tempted to renege on payments, collateral may be necessary to secure a transaction. 
However, unsecured trading is desirable as pledging collateral is costly for the agent with an investment opportunity.

Trading without collateral is feasible when trade is repeated, and agents can condition current and future terms of trade on the success of past transactions. If agents have information about past financial transactions, those traders with an investment opportunity that have previously reneged on payments can be excluded from the uncollateralized market. However, when agents meet at random, it is not trivial to determine what information a trader collects over time. The approach I take is to consider that access to information is granted through a network of bilateral links. A link that connects two agents in a network grants each of them access to information about the other. Ultimately, the information set of an agent depends on his position in the network.

In a network, a pair of agents can trade directly, or indirectly, through intermediaries. If a pair of agents trades directly, the agent with a liquidity surplus receives her reservation value while the agent with an investment opportunity retains the surplus. If agents trade indirectly, intermediaries require to be compensated for facilitating the trade. More precisely, the agent with an investment opportunity (as the one that benefits from trading without collateral) is charged a fee that depends positively on the number of intermediaries that facilitate the trade. In this case, the agent with a liquidity surplus continues to receive her reservation value, while the agent with an investment opportunity sees his share of the payoff reduced depending on the number of intermediaries that facilitate the trade. The more intermediaries are involved in the transaction, the lower will be the share of the surplus that each party receives.

I show that the benefits of repeated trade shape the nature of interactions in the market and ultimately give rise to intermediation. As a first step, I analyze the trade-off between trading without or against collateral in a static framework, for a given network. Then, I study which networks arise in equilibrium, when agents face informational frictions as they have to pay a small cost to acquire information.

In a given network, agents trade without collateral if the agents with an investment opportunity find the outside option of trading against collateral sufficiently expensive. Intermediaries are instrumental for successfully trading without collateral. In particu- 
lar, traders rely on intermediaries to discriminate against those agents that have reneged on payments in the past. However, the longer the chain of intermediation is, the more appealing trading against collateral is.

As agents are allowed to choose with whom to form relationships, intermediation arises endogenously. When there are informational frictions, agents choose to trade without collateral in dealer-centric markets, where one agent acts as intermediary and trading counterparty for all other agents. In this case, agents find that paying intermediation fees is less expensive than acquiring information. When there are no informational frictions, markets are as if they are perfectly transparent. Since traders can freely access the complete history of financial transactions, each agent trades directly in any given period with the counterparty he has been matched.

Inefficiencies arise whenever agents trade against collateral. Their decision is driven by the relative difference between the expected return of the assets and the opportunity cost of collateral. In particular, the benefit of trading assets without collateral over the counter decreases as this difference increases. As the relative difference is high, assets are traded against collateral in a setup similar to an exchange. In addition, inefficiencies are more likely to arise when markets are illiquid, and they are more pronounced in the presence of informational frictions.

The interest in the formation of relationships between traders in OTC markets is largely motivated by the absence of formal institutions in these markets that have non-negligible trading volumes (the gross market value of credit default swaps reached 5 billions dollars at its peak in December 2008). Relationships in OTC markets carry implications for both the terms of trade, as well as for the pattern of interactions between traders. On the one hand, when agents develop relationships, they can negotiate terms of trade that they cannot access otherwise. Indeed, Bernhardt et al. (2005) find evidence that dealers on the London Stock Exchange will offer greater price improvement to more regular customers. They explain this finding through a model where traders can use an intertemporal threat to switch dealers if they are not sufficiently rewarded for placing large orders. Similarly, a study of the Portuguese interbank market by Cocco et al. (2009) shows that banks with a larger reserve imbalance are more likely to borrow funds from banks with whom 
they have a relationship, and to pay a lower interest rate than otherwise. On the other hand, the pattern of interactions reveals interesting features as well. For instance, Upper and Worms (2004) map the German interbank market and identify a two-tiered banking system. Banks belonging to the upper tier have lending relationships with a variety of other banks belonging to the same tier, and banks in the lower tier transact with banks in the upper tier. This paper explains the dealer-centric nature of some OTC markets in a model where agents have an incentive to form networks of relationships with a coreperiphery structure.

\section{Related Literature}

This paper relates to several strands of literature. The more relevant studies are those on contract enforcement, bilateral trading in OTC markets and dynamic network formation games.

The literature on contract enforcement is substantial. The general aim of this literature is to show that repeated interactions alleviate problems that arise when there is limited enforcement of contracts. Allen and Gale (1999), Kletzer and Wright (2000) and Levin (2003) propose models where contracts are incomplete, either because transaction costs make it too costly to write explicit contracts or simply because the terms of the contract are not verifiable by a third party (i.e. a court). However, when two parties interact repeatedly, they can implement the first-best contract. Several other papers depart from the assumption that the same two parties interact with each other, and consider a large population of agents that are matched at random to interact every period. In this case, whether contracts can be enforced or not depends crucially on how much information is available to each agent. Klein (1992) approaches this issue in a model of repeated interaction between businesses that decide whether to give credit, and consumers who decide whether to pay her bill. The author suggests that a credit bureau can hold a record of whether each consumer has ever defaulted or not. Greif (1993) and Tirole (1996) propose an enforcement mechanism based on community reputation. In this paper I also study whether it is possible to enforce first-best contracts through repeated interactions when agents are randomly matched to trade. However, I consider that agents have access 
to information via network of bilateral relationships. I show that agents can rely on their network to trade the efficient contracts. In addition, I allow agents to choose how to form these relationships and analyze which networks emerge in equilibrium.

In the past decade, a series of papers has studied trading in over-the-counter markets. Most of these studies have been concerned with explaining asset prices through trading frictions. Acharya and Pedersen (2005) study the effect on asset prices of an exogenously specified trading cost. Duffie, Garleanu and Pedersen (2005, 2007) endogenize the trading frictions arising through search and bargaining, and show their effects on asset prices. Some other papers look at trading in exchanges and analyze how information is transmitted through a network and embedded in prices (Colla and Mele (2010) and Ozsoylev and Walden (2009)). Complementary to this literature, I propose a model where agents can overcome frictions that arise from search by trading through a network of relationships.

Methodologically, this model draws from the literature on networks. The general concept of a network is quite intuitive: a network describes a collection of nodes and the links between them. Situations, such as the one I study, where agents form or severe connections depending on the benefits they bring are modeled through a game of network formation. A rapidly growing literature on network formation games has developed in the past decade, introducing various approaches to model network formation and proposing several equilibrium concepts (Bala and Goyal, 2000, Bloch and Jackson, 2007, Jackson and Wolinsky, 1996). In the context of these initial models, Goyal and Vega-Redondo (2007) analyze the role of intermediaries in bridging structural holes in social networks. Particularly relevant for my framework is the equilibrium concept proposed to analyze dynamic network formation games by Dutta et. al (2005).

Although there are numerous applications of these models in the social science context, the research on financial networks is still at an early stage. Allen and Babus (2008) provide a comprehensive survey of this literature. Most of the existing research using network theory concentrates on issues such as financial stability and contagion. For instance, Leitner (2007) investigates the possibility of private bail-outs organized by a social planner. Allen, Babus and Carletti (2010) and Zawadowski (2010) concentrate on the interaction between financial connections due to overlapping portfolio exposures and systemic risk. 
The role of intermediaries in financial networks has been analyzed thus far by Gale and Kariv (2007), Gofman (2011) and Fainmesser (2011). The first two papers study how the presence of intermediaries affects the efficient allocation of assets for a fixed network. In Gale and Kariv intermediation creates inefficiencies as it delays trade, while in Goffman inefficiencies arise when agents bargain through intermediaries. In contrast, I show that intermediation can alleviate inefficiencies in over-the-counter markets. In a very recent work, Fainmesser (2011) also studies how intermediaries can informally enforce the repayment of loans by borrowers, and identifies which networks sustain trade. However, which agents are intermediaries remains exogenous. Conversely, in the model I provide, certain agents endogenously assume the role of intermediaries to facilitate repeated interactions between traders in the market.

The paper is organized as follows. The following section introduces the model setup. I explain the role of relationships in allowing agents to trade risky assets without collateral in section 3. The dynamics of a network of relationships and is analyzed in section 4 . Section 5 discusses the role of the asset properties and possible inefficiencies. Section 6 concludes.

\section{The Model}

\subsection{The Basic Setup}

Consider a set $N=\{1,2, \ldots, 2 n\}$ of risk-neutral agents who participate in the market. Half the agents, in the set $\mathcal{L}=\{1,2, \ldots, n\}$, have a liquidity surplus. The other half, in the set $\mathcal{I}=\{n+1, n+2, \ldots, 2 n\}$, have an investment opportunity. To make the exposition easier to follow, I refer to an agent with a liquidity surplus as she and to an agent with an investment opportunity as he. All agents are infinitely lived, and discount the future at the constant rate $\delta$. An agent $i \in \mathcal{L}$ with a liquidity surplus is endowed every period with one unit of cash, which can be stored at no cost until the end of the period. An agent $j \in \mathcal{I}$ with an investment opportunity is endowed with a riskless asset which yields a return of $r \geq 1$ at the end of every period. In addition, he has an opportunity to invest in a risky asset which yields a return $\theta_{j}^{t}=\{R, 0\}$ by the end of the period with probability 
$p$ and $(1-p)$, respectively. The returns of the risky asset are independently distributed across agents, as well as over time. I assume that $E\left(\theta_{j}^{t}\right) \geq r$ for all $j$ and $t$.

To finance the investment, an agent with an investment opportunity needs to borrow one unit of funds from an agent with a liquidity surplus at the beginning of each period, $t$. The implicit assumption is that liquidating any part of the riskless asset at the beginning of the period to self-finance the investment is costly. An agent with the liquidity surplus finances an agent with an investment opportunity only if she is indifferent between participating and not participating in the transaction (i.e. she expects to be repaid her reservation value). In exchange for borrowing the money, the agent with an investment opportunity issues a security that specifies a payoff

$$
f=1,
$$

to be received at the end of the period, independent of the realization of the risky asset.

However, I assume that enforcement is limited, which allows an agent with an investment opportunity to abscond with cash flows. Anticipating that an agent with an investment opportunity is tempted to renege on payments, an agent with a liquidity opportunity can require him to pledge the riskless asset as collateral to secure the transaction at the beginning of the period. Although effective in guaranteeing payments, pledging collateral is costly for the agent with an investment opportunity. In practice, pledging collateral blocks relatively liquid funds that can otherwise be invested at a positive return elsewhere. In the Kiyotaki and Moore (1997) world, collateral is costly because the borrower's valuation of the collateral is a fraction of the lender's. I assume as well that when an agent with a liquidity surplus liquidates the collateral, she only receives a return of 1 .

Alternatively, an agent with a liquidity surplus can trade without collateral and credibly threaten to permanently exclude from the unsecured market any agent with an investment opportunity that reneges on payments.

An agent with an investment opportunity incurs, thus, an opportunity cost when trading against collateral. The choice between trading with or without collateral is studied in detail Section 3, where I provide conditions under which trading without collateral can 
be supported in equilibrium. For the remaining of the current section I describe the arrival of trading opportunities, and how financial transactions take place.

\subsection{The Matching Technology}

Typically, in OTC markets parties that wish to trade must search for each other. To capture search frictions, I assume that every period each agent with a liquidity surplus is paired uniformly at random with one and only one agent with an investment opportunity at the beginning of each period.

Formally, a matching $\mathbf{m}$ is simply a collection of disjoint pairs as follows

$$
\mathbf{m}=\{(i, j) \mid(i, j) \cap(k, l)=\emptyset \text { for any } i, k \in \mathcal{L} \text { and } j, l \in \mathcal{I}\} .
$$

The set of all such matchings on $N$ is denoted by $\mathcal{M}(N)$. At any time $t$, a matching $\mathbf{m}^{t}$ is randomly drawn from $\mathcal{M}(N)$. The cardinality of $\mathcal{M}(N)$ is given by $|\mathcal{M}(N)|=n(n-1) \ldots 1$. Then, the probability that a pair of agents $(i, j)$ is matched at date $t$ is

$$
\operatorname{Pr}\left[(i, j) \in \mathbf{m}^{t}\right]=\frac{1}{n}
$$

The number of agents in the market, $2 n$, determines the frequency at which a pair of agents $(i, j)$ is matched, such that the larger $n$ is, the lower the frequency is.

\subsection{Financial Transactions}

Once the counterparties are paired through the matching technology, there are two procedures through which the agent with a liquidity surplus can finance the agent with an investment opportunity: direct financing and indirect financing.

\section{Direct Financing}

Under the direct financing procedure, an agent with a liquidity surplus finances her counterparty set by the matching technology through a direct transaction.

When agents trade without collateral, the agent with a liquidity surplus lends one unit of funds at the beginning of the period to the agent with an investment opportunity. At 
the end of the period, he makes a repayment $f_{j}^{t} \in\{0,1\}$. The payoff of an agent with a liquidity surplus from the transaction is $f_{j}^{t}$. The agent with an investment opportunity retains any surplus from the return of the risky and of the riskless asset, $\theta_{j}^{t}+r-f_{j}^{t}$.

When agents trade against collateral, the agent with an investment opportunity borrows one unit of funds and pledges collateral at the beginning of the period. At the end of the period, if he repays 1 to the agent with a liquidity surplus, he retrieves back the collateral and receives a payoff of $\theta_{j}^{t}+r-1$. If he repays 0 , the agent with a liquidity surplus liquidates the collateral, and the agent with an investment opportunity receives a payoff of $\theta_{j}^{t}$. The payoff of an agent with a liquidity surplus from the transaction is 1 , independent of the actions of the agent with an investment opportunity.

\section{Indirect Financing}

In the second situation, one or more agents mediate the transaction between an agent with a liquidity surplus and an agent with an investment opportunity. Agents that are involved this way in the creation of the surplus are called intermediaries. An intermediary is either an agent with a liquidity surplus or an agent with an investment opportunity. However, not all agents will act as intermediaries. Thus, intermediaries can be seen as broker-dealers: they intermediate trade between other agents, and they also take positions of their own.

Agents have the possibility to trade both with and without collateral through intermediaries. Suppose that $(i, j)$ is a pair matched to trade at time $t$ and the sequence $\left(i_{1}, i_{2}, \ldots, i_{k}\right)^{t}$ are the intermediaries that facilitate the transaction in this order. Let $i$ be the agent with a liquidity surplus and $j$ the agent with an investment opportunity. The sequence $\left(i_{1}, i_{2}, \ldots, i_{k}\right)^{t}$ forms a path between $i$ and $j$. The distance, $d^{t}(i, j)$, between $i$ and $j$ represents the number of intermediaries on the path between $i$ and $j$ at time $t: d^{t}(i, j)=k$. The agent with a liquidity surplus finances the agent with an investment opportunity through a series of $\left(d^{t}(i, j)+1\right)$ successive lending transactions: $\left(i, i_{1}\right),\left(i_{1}, i_{2}\right), \ldots,\left(i_{k-1}, i_{k}\right),\left(i_{k}, j\right)$. Each transaction is covered by a contract whose terms depend on whether agents trade with or without collateral.

Consider first that agents trade without collateral. At the beginning of the period, the agent with a liquidity surplus lends her unit of cash to the first intermediary $i_{1}$, who 
passes it on down the path until it reaches $j$. At the end of the period, the agent with the investment opportunity makes a repayment $f_{j}^{t} \in\{0,1\}$ to the agent with a liquidity surplus, via the path of intermediaries $\left(i_{1}, i_{2}, \ldots, i_{k}\right)^{t}$ in reverse order. When agents trade without collateral, intermediaries will be instrumental in verifying whether the agent with an investment opportunity makes the due payment at every date $t$. They will do so conditional on being compensated for facilitating the transaction. When intermediaries have bargaining power, the compensation they require depends on the position they occupy in the network. More precisely, the agent with an investment opportunity (as the one that benefits from trading without collateral) is charged a fee that depends positively on the number of intermediaries that facilitate the trade. Such a fee structure can be microfounded, as discussed in Section 5.3, through a sequential bargaining procedure in which the agent with an investment opportunity bargains in turn with the $d^{t}(i, j)$ intermediaries on how to divide the surplus from trade. However, since the results in this paper are robust to any fee structure that depends on the number of intermediaries, I adopt a simpler specification. In particular, I assume each intermediary receives a fee that is proportional to the payment, $f_{j}^{t}$, the agent with an investment opportunity makes at the end of the period. The fee decreases with the distance between the intermediary and the agent with an investment opportunity. In particular, an intermediary $i_{l}$ who is at a distance $d^{t}\left(i_{l}, j\right)$ from the agent $j$ with an investment opportunity receives a fee of $\gamma^{d^{t}\left(i_{l}, k\right)+1} f_{j}^{t}$. The total amount an agent with an investment opportunity has to pay in fees is $\frac{\gamma-\gamma^{d^{t}(i, j)+1}}{1-\gamma} f_{j}^{t}$. At the end of the period, his payoff from the transaction is the surplus from the return of the risky and the riskless asset, $\theta_{j}^{t}+r-\frac{1-\gamma^{d^{t}(i, j)+1}}{1-\gamma} f_{j}^{t}$. To insure that an agent with an investment opportunity always receive positive payoffs, I assume that $\gamma$ is small relative to $r: \gamma \leq \frac{r-1}{r}$. . The payoff of an agent with a liquidity surplus from the transaction is, as before, $f_{j}^{t}$. Figure $1(\mathrm{~b})$ illustrates the payoffs that accrue to a pair of agents matched to trade and to the intermediaries that facilitate the transaction.

Trading against collateral takes place in a similar fashion. However, intermediaries do not receive any compensation for facilitating trade. This assumption reflects that a pair of matched agents can trade directly against collateral. In this case, all $\left(d_{t}(i, j)+1\right)$ transactions are subject to collateral requirements. However, intermediaries re-use the 
collateral received from the agent with an investment opportunity to secure transactions. Thus, pledging collateral is costly only for the agent with an investment opportunity. Both the agent with a liquidity surplus and the agent with an investment opportunity receive the same payoffs as in the direct financing procedure, while intermediaries receive 0 .

\section{Information and Repeated Trade}

Trading without collateral is feasible only if parties interact repeatedly, and agents can base current and future terms of trade on the success of past trades. When trade is repeated, those traders with an investment opportunity that have previously reneged on payments can be excluded from the uncollateralized market. However, traders need to have at least partial access to the history of financial transactions to decide whether to trade without collateral or to require collateral.

The history of financial transactions up to date $t$ records the sequence of past collateral

requirements and payments for all agents, as follows. Let $\mathbf{z}^{t}=\left(z_{1}^{t}, z_{2}^{t}, \ldots, z_{n}^{t}\right)$ be the vector of collateral requirements that the agents with the liquidity surplus impose at the beginning of date $t$, with $z_{i}^{t} \in\{0,1\}$. When collateral is required to secure the transaction, $z_{i}^{t}=1$. Otherwise, $z_{i}^{t}=0$. Similarly, let $\mathbf{f}^{t}=\left(f_{n+1}^{t}, f_{n+2}^{t}, \ldots, f_{2 n}^{t}\right)$ be the vector of repayments that the agents with the investment opportunity make at the end of date $t$, with $f_{j}^{t} \in\{0,1\}$. Then the history of financial transactions at date $t$ is given by $\mathbf{h}^{t}=\left(\mathbf{z}^{t-1}, \mathbf{f}^{t-1}, \mathbf{z}^{t-2}, \mathbf{f}^{t-2}, \ldots, \mathbf{z}^{1}, \mathbf{f}^{1}\right)$. The set of possible date $t$ histories is $\mathcal{H}^{t}$. The private history of an agent $i$ with a liquidity surplus, $h_{i}^{t}$, describes the collateral requirements she has imposed up to date $t$, such that $h_{i}^{t}=\left(z_{i}^{t-1}, z_{i}^{t-2}, \ldots, z_{i}^{1}\right)$. Similarly, let $h_{j}^{t}$ be the private history of an agent $j$ with an investment opportunity describing the payments he has made up to date $t$, such that $h_{j}^{t}=\left(f_{j}^{t-1}, f_{j}^{t-2}, \ldots, f_{j}^{1}\right)$.

In over-the-counter markets, search obscures traders' access to the history of financial transactions. As agents meet at random, there is no trivial way to determine what information an agent collects over time. The personal history that an agent observes is the history of financial transactions as partitioned by a network $g^{t}$. A network specifies a set of links between agents. A link that connects two agents in a network $g^{t}$ grants each of 
them access to information about the other. In particular, a link $i j$ between traders $i$ and $j$ allows trader $i$ to access the history of trader $j, h_{j}^{t}$. I assume that links are bilateral, which implies that the link $i j$ allows trader $j$ as well to access the history of trader $i$, $h_{i}^{t}$. Then, the personal history that each agent observes is the set of private histories of traders with whom he/she has a link and includes his/her own private history.

Agents can condition both collateral requirements and payments on the history of financial transaction that they observe. In other words, an agent with a liquidity surplus has a trading strategy that specifies whether to trade without or against collateral at each future date, for any (personal) history she observes. Similarly, an agent with an investment opportunity has a trading strategy that specifies the payments he makes at each future date, for any (personal) history he observes. Then, trading without collateral is selfenforcing if it describes a strategy profile that is a sequential equilibrium of the repeated interaction game. As in Mailath and Samuelson (2006), a trading strategy profile is a sequential equilibrium if, after every personal history, each trader is best responding to the behavior of the other players, given beliefs over the personal histories of the other traders that are "consistent" with the personal history that she or he has observed.

In the remaining of this section I analyze two cases. First, as a benchmark case, I assume that all agents are connected with all other agents. In this case, each agent has perfect information about the history of financial transactions. The case of complete networks is analyzed in Section 3.1. Second, I consider the more general case where there exist agents that are not directly connected by a link to each other. In this case, at least some traders have only limited access to the history of financial transaction. The case of incomplete networks is explored in Section 3.2.

\subsection{Perfect Information - The Benchmark Case}

To illustrate the basic mechanics of the model, I start by considering the case of complete networks, when all agents are connected with all other agents. At each date $t$, the personal history of any trader is the history of financial transactions $\mathbf{h}^{t}$. This is equivalent to assuming that the history of financial transactions is publicly observable at every date $t$ and it is common knowledge to all traders. A possible interpretation for this situation is 
that a credit bureau records credit histories and provides this information to the market free of charge. I show that there exists an equilibrium when all agents trade without collateral, provided the opportunity cost of pledging collateral, $(r-1)$, is sufficiently high. The discussion in this section is based on Kandori (1992).

The timing sequence in every period is as follows. At the beginning of each period $t$, agents are matched to trade. Then, all agents observe the history $\mathbf{h}^{t}$. Consequently, each agent $i$ with a liquidity surplus decides whether to trade without collateral $\left(z_{i}^{t}=0\right)$ or against collateral $\left(z_{i}^{t}=1\right)$. Transactions take place accordingly. At the end of every date $t$, when the asset matures, each agent $j$ with an investment opportunity makes a payment $f_{j}^{t}$

The following proposition summarizes the necessary condition for trading without collateral to be self-enforcing.

Proposition 1 An equilibrium when all agents trade without collateral at every date can be sustained if the opportunity cost of pledging collateral is sufficiently high, such that

$$
r-1 \geq \frac{1}{\delta(1-p)}(1-\delta)
$$

Proof. See Appendix.

The intuition for this result is simple. Suppose that agents start by trading without collateral at date 1 . The trading strategy of an agent $i$ with a liquidity surplus depends on the reputation of the agent $j$ with an investment opportunity with whom she is matched at a given date $t>1$. Thus, her strategy prescribes she trades without collateral unless he has repaid $f_{j}^{\tau}=0$ at least one date $\tau<t$ in the past. The trading strategy of an agent $j$ with an investment opportunity depends on whether he trades without or against collateral at a given date $t$. When trading without collateral, his strategy prescribes that he repays $f_{j}^{t}=1$ at the end of the period. Otherwise, if he is required to pledge collateral, his strategy prescribes that he repays $f_{j}^{t}=1$ when $\theta_{j}^{t}=R$ and $f_{j}^{t}=0$ when $\theta_{j}^{t}=0$ at the end of the period. However, if he repaid $f_{j}^{\tau}=0$ at least one date $\tau$ in the past, he will repay 0 thereafter in all periods when he trades without collateral. This implies that an agent that has reneged on a payment in a period when trading without collateral, he will 
renege on payments thereafter. ${ }^{1}$

Such a strategy profile supports trading without collateral as an equilibrium of the repeated random matching trading game. As soon as an agent with an investment opportunity reneges on his obligations, no agent with a liquidity surplus will accept to finance him unless he pledges collateral. In the absence of information about whether transactions have been previously secured by collateral or not, an agent with a liquidity surplus excludes from the unsecured market any agent with an investment opportunity that has repaid 0 at least once in the past. Since agents with a liquidity surplus are indifferent between trading with or without collateral, such a threat is credible. Thus, an agent with an investment opportunity that has repaid 0 at a given date $t$ is bound to trade against collateral thereafter. Then, an agent $j$ with an investment opportunity weighs the longterm benefit from trading without collateral, when he receives the return of the riskless asset, $r$, in every period against the one time gain of retaining all the surplus and paying 0 . Thus, every period $t$ he trades without collateral, he makes a payment $f_{j}^{t}=1$ if

$$
\theta_{j}^{t}+r-1+\frac{\delta}{1-\delta}(p R+r-1) \geq \theta_{j}^{t}+r+\frac{\delta}{1-\delta} p(R+r-1)
$$

In an equilibrium when agents trade without collateral an agent $j$ with an investment opportunity expects to receive per period a total payoff of

$$
\pi_{j \in \mathcal{I}}^{U}=p R+r-1
$$

which incudes the return from the illiquid asset. The agent $i$ that has a liquidity surplus expects to receive per period her reservation value

$$
\pi_{i \in \mathcal{L}}^{U}=1
$$

An equilibrium when agents trade against collateral can be sustained for any opportunity cost $(r-1)$ of pledging collateral. However, if $(r-1)$ is small enough, trading against collateral is the only equilibrium.

\footnotetext{
${ }^{1}$ Note that, in the simpler case when the return $\theta_{j}^{t}=R$ with probability $p=1$ for any $j$ and $t$, a repayment $f_{j}^{t}=0$ represents immediately a defection of an agent $j$ with an investment opportunity.
} 
Corollary 1 If $(r-1)<\frac{(1-\delta)}{\delta(1-p)}$, there exists a unique equilibrium when all agents trade against collateral.

Proof. See Appendix.

Thus, even in the case of perfect information, inefficiencies arise if the opportunity cost of trading against collateral is sufficiently low.

In an equilibrium when agents trade against collateral the total payoff an agent $j$ with an investment opportunity expects to receive per period depends on whether the agent with a liquidity surplus liquidates the collateral or not, such that

$$
\pi_{j \in \mathcal{I}}^{C}=p(R+r-1)
$$

An agent $i$ that has a liquidity surplus either receives a payment of 1 or liquidates the collateral, which implies that her payoff is always

$$
\pi_{i \in \mathcal{L}}^{C}=1
$$

Public observability plays a critical role for the result in Proposition 1. In this case, each agent has as strong an incentive to make due payments as if he faced the same partner in each period. This is true even when the chance of meeting the same partner in the future is very small, or even zero. Observability in the market is a substitute for having a long-term frequent relationship with a fixed partner.

\subsection{Informational Linkages}

The second situation I consider is when networks are incomplete, such that there exist agents that are not directly connected by a link to each other. In this case, an agent's personal history is a subset of the history of financial transactions $\mathbf{h}^{t}$. I show how agents trade without collateral through a network of relationships and I describe how an agent's payoff depends on the position that he/she has in the network.

Agents can condition whether to trade without or against collateral on the information they access through their links in the network. For this, however, they may need to trade 
through intermediaries. ${ }^{2}$ Which agents act as intermediaries in a given period $t$ depends on the network structure $g^{t}$ and the matching $\mathbf{m}^{t}$. Figure 1 illustrates a possible network where $i$ and $j$ are matched at time $t$ and the corresponding sequence of intermediaries that facilitates the transaction. If there is more than one sequence of intermediaries that can possibly facilitate the transaction between $i$ and $j$, agents choose the shortest path. Depending on the matching realized each period, a link in the network $g$ connects either two agents that are matched to trade, or intermediaries on a path between a matched pair. Agents have the possibility to trade without and against collateral through a network. If there exists a link between a pair of agents that is matched to trade, then they can use the direct financing procedure. If a matched pair of agents needs to trade through intermediaries, then they use the indirect financing procedure.

When agents are embedded in a network, the sequence of events in every period is as follows. At the beginning of each period $t$, agents are matched to trade. Each agent observes the private history of each of his neighbors in the network $g^{t}$. Then, agents decide whether to trade without or against collateral. In particular, if there exists a link between a pair of agents that is matched to trade, then the agent with a liquidity surplus decides whether to require collateral or not. If a matched pair of agents needs to trade through intermediaries, then the intermediary that is closest to the agent with an investment opportunity decides whether to require collateral or not. Transactions take place accordingly. At the end of every date $t$, when the asset matures, each agent $j$ with an investment opportunity makes a payment $f_{j}^{t}$, and possibly pays fees to the intermediaries.

It is important to stress that the information accessed through links concerns only contracts traded on an agent's behalf, and not contracts that he/she intermediates. Nevertheless, relationships grant sufficient access to information such that traders become concerned about the consequences of their actions on their reputation. I show that agents trade without collateral provided the benefits they acquire by doing so overcome the fees

\footnotetext{
${ }^{2}$ Agents can choose to trade directly with the counterparty they have been matched at a certain date, and circumvent intermediaries. However, I consider that when a pair of agents does not trade through the network, they cannot see the identity of the their match and their action is not recorded in their personal history. This is as when a trader places an order on an electronic trading platform that is matched anonymously with a counterparty. In this case, agents cannot exploit the informational advantage that the network offers them, and trading aside of the network is as if interactions are one shot. Consequently, agents will be trading against collateral whenever they are not trading through the network.
} 
they pay to intermediaries.

Proposition 2 Suppose that all agents are embedded in a network $g$ and $\bar{d}$ is the maximum number of intermediaries that facilitate trade between any two agents. Then, there exists an equilibrium when agents trade without collateral if the opportunity cost of pledging collateral is sufficiently high to more than overcome the fees that intermediaries charge

$$
r-1 \geq \frac{1}{\delta(1-p)}\left(\frac{1-\gamma^{\bar{d}+1}}{1-\gamma}-\delta\right)
$$

Proof. See Appendix.

The intuition for this result is as follows. Suppose that agents start by trading without collateral at date 1 . The trading strategy of an agent $i$ with a liquidity surplus prescribes whether to trade without or against collateral if matched with agent $j$ at date $t$. When $i$ and $j$ have a link, she conditions her decision on the reputation of the agent $j$ that she can observe directly. In particular, she always trades without collateral unless he has repaid $f_{j}^{\tau}=0$ at least one date $\tau<t$ in the past. When two agents matched to trade do not have a direct relationship, the agent with a liquidity surplus trades as requested by intermediaries. That is, she relies on intermediaries to discriminate against traders that renege on payments. For instance, when the sequence $\left(i_{1}, i_{2}, \ldots, i_{k}\right)^{t}$ intermediates the trade between $i$ and $j$ at time $t$, the last intermediary $i_{k}$ decides to trade without collateral or to require collateral based on the history of agent $j, h_{j}^{t}$, that he/she observes. The strategy of an intermediary that facilitates trade between a matched pair of agents prescribes that he/she always trades without collateral unless the agent with an investment opportunity has repaid $f_{j}^{\tau}=0$ at least one date $\tau<t$ in the past. The trading strategy of an agent $j$ with an investment opportunity depends on whether he trades without or against collateral at a given date $t$. When trading without collateral, his strategy prescribes that he repays $f_{j}^{t}=1$ and the corresponding intermediation fees at the end of the period. Otherwise, if he is required to pledge collateral, his strategy prescribes that he repays $f_{j}^{t}=1$ when $\theta_{j}^{t}=R$, and $f_{j}^{t}=0$ when $\theta_{j}^{t}=0$ at the end of the period. However, if he repaid $f_{j}^{\tau}=0$ at least one date $\tau$ in the past, he will repay 0 and no intermediation fees thereafter in all periods when he trades without collateral. This implies that an agent that has reneged 
on a payment in a period when trading without collateral, he will renege on payments thereafter. I denote this strategy profile by $\sigma^{*}$.

The payoffs that intermediaries receive are important for supporting the trading strategy profile $\sigma^{*}$ as an equilibrium for two reasons. First, the fees that intermediaries charge for facilitating trade between a matched pair are contracted on the payment that the agent with an investment surplus makes. This aligns the incentives of intermediaries with those of the agent with a liquidity surplus. Since an agent with an investment opportunity that reneges on a due payment does not pay fees either, intermediaries cannot be tempted to trade without collateral with a defector at the expense of the agent with a liquidity surplus. Second, the payment that an agent with an investment opportunity makes is verifiable. This implies that intermediaries cannot misreport that an agent with an investment opportunity has reneged on payment when he did not in order to retain the fees due to other intermediaries or the final payment to the agent with a liquidity surplus.

Under the strategy profile $\sigma^{*}$, trading without collateral is self-enforcing when for any trader the expected long-run opportunity cost of trading against collateral is at any point in time larger than the one time gain from defection. If an agent investment opportunity reneges on his obligations at a given date, all the agents with whom he has a relationship refuse to trade uncollateralized with him thereafter. In any given period, such a threat comes from either agents with a liquidity surplus or from intermediaries. Any agent with a liquidity surplus is indifferent between trading without collateral or requiring collateral, so that her threat is credible. Moreover, it is understood that if an agent $j$ with an investment opportunity repays $f_{j}^{t}=0$ at date $t$, he does not pay intermediations fees either. This implies that the threat of intermediaries is credible as well, since they do not receive any benefits from an agent that reneges on payments. Then, an agent $j$ with an investment opportunity weighs the long-term benefit from trading without collateral against the one time gain of retaining all the surplus and paying 0 . On the long-run, he receives the return of the riskless asset, $r$, in every period but foregoes some of his share of the surplus by paying intermediation fees.

An interesting feature of the equilibrium strategy profile $\sigma^{*}$ is that an agent with an investment opportunity that acts as an intermediary can still facilitate trade for others 
and receive benefits from intermediation, even if he has reneged on his due payments. The reason is that his trading strategy as an intermediary is not conditional on his behavior as an agent with an investment opportunity, nor on his past as an intermediary.

In a network, agents derive two types of benefits along the equilibrium path of trading without collateral. On the one hand, they gain benefits from trading. On the other hand, they may gain rents from intermediating transactions between other agents. Then, an agent with a liquidity surplus $i$ embedded in a network $g^{t}$ expects to receive at every date $t$ a net payoff of

$$
\pi_{i \in \mathcal{L}}^{U}\left(g^{t}\right)=1+\sum_{\substack{\left(l, l^{\prime}\right) \in \mathbf{m}^{t} \\ i \in P_{t}\left(l, l^{\prime}\right)}} \frac{1}{n} \gamma^{d^{t}\left(i, l^{\prime}\right)+1}
$$

where $P_{t}\left(l, l^{\prime}\right)$ represents the set of agents $\left(i_{1}, i_{2}, \ldots, i_{m}\right)$ that act as intermediaries between two agents $l$ and $l^{\prime}$ that trade without collateral at time $t$. An agent with an investment opportunity sees his share of the surplus reduced depending on the number of intermediaries that facilitate the trade when trading without collateral. He expects to receive per period

$$
\pi_{j \in \mathcal{I}}^{U}\left(g^{t}\right)=\sum_{k \in \mathcal{L}} \frac{1}{n}\left[p R+r-\frac{1-\gamma^{d^{t}(j, k)+1}}{1-\gamma}\right]+\sum_{\substack{\left(l, l^{\prime}\right) \in \mathbf{m}^{t} \\ j \in P_{t}\left(l, l^{\prime}\right)}} \frac{1}{n} \gamma^{d^{t}\left(j, l^{\prime}\right)+1} .
$$

The first part of the summation in (8) and (9), respectively, represents the expected benefit an agent derives from being matched to trade. An agent with a liquidity surplus, $i$, expects to receive a repayment of 1 independent on whom she is matched to and on whether she trades with or without collateral. An agent with an investment opportunity is matched to trade with another agent $k$ at a distance $d(j, k)$ with probability $\frac{1}{n}$, in any given period. From each of his potential matches, he expects a net gain of $\left[p R+r-\frac{1-\gamma^{d^{t}(j, k)+1}}{1-\gamma}\right]$. The second part of the summation in (8) and (9) represents the intermediation rents an agent can acquire from the network $g^{t}$. An agent that lies on a path between two agents $l$ and $l^{\prime}$ receives a share of the surplus only if $l$ and $l^{\prime}$ are matched trade at time $t$ which happens with probability $\frac{1}{n}$. In a period when an agent acts as an intermediary between between the pair $\left(l, l^{\prime}\right)$, her/his share of the surplus will depend on how many other intermediaries 
are between $\left(l, l^{\prime}\right): \gamma^{d^{t}\left(i, l^{\prime}\right)+1}$.

All players receive benefits from being matched to trade. However, some players may act as intermediaries and acquire additional gains, at the expense of others. This crucially affects agents' decision on how to form relationships. If forming relationships implies trading through intermediaries, then agents matched to trade need to forego part of their share. The more intermediaries are involved in a transaction between a pair of agents $(i, j)$, the lower will be the share the agent with an investment opportunity receives in the division of the surplus.

To summarize, the aggregate payoff of agent $i$ with a liquidity surplus over time is

$$
V_{i \in \mathcal{L}}^{U}=\sum_{t} \delta^{t} \pi_{i}^{U}\left(g^{t}\right)
$$

while the aggregate payoff of agent $j$ with an investment opportunity over time is

$$
V_{j \in \mathcal{I}}^{U}=\sum_{t} \delta^{t} \pi_{j}^{U}\left(g^{t}\right)
$$

where I allow the possibility for the network $g$ to change over time.

\section{Network Dynamics}

The interest in this paper is to understand how intermediation arises endogenously. For this, I study the formation of relationships between traders in over-the-counter markets in a dynamic setting. I show that the nature of the equilibrium depends on the existence of informational frictions in the economy.

To model informational frictions, I consider that each trader must pay a cost $\kappa \geq 0$ per link in every period, unless he/she uses the link for a transaction. A link is used in a transaction when it connects two agents that trade directly a contract (either without or against collateral) or it connects intermediaries on a path between a matched pair. For instance, suppose that $i$ and $j$ are matched to trade in period $t$, as shown in Figure 1. Then, all the links on the path between $i$ and $j$ are used in at least one transaction. Hence, the cost $\kappa$ for accessing information over these links is waived for $i, j$, and the 
three intermediaries. However, if the following period $j$ is matched with $i_{3}$, then the link between $i_{3}$ and $i_{2}$ is no longer used in a transaction and it costs both agents $\kappa$.

When access to information is costly, agents face a trade-off. On the one hand, linking to more agents is desirable as agents increase their chance to trade without collateral directly, without paying intermediation fees. On the other hand, maintaining relationships with many agents becomes too expensive. To illustrate this effect, consider the following example. Suppose that each agent with an investment opportunity is connected with all agents with a liquidity surplus. In this case, an agent with an investment opportunity can trade directly without with the counterparty he is matched in any given period. However, he uses only one of his links for a transaction every period. Although he saves on intermediation fees, he has to pay the cost $\kappa$ for all the $(n-1)$ links he does not use. However, by taxing agents the cost $\kappa$ only in periods in which they do not use a link, agents with a liquidity surplus that are at the periphery of a network (and, thus, not in a position to intermediate trade) are still willing to maintain links.

I analyze the formation of strategic relationships in a dynamic framework, where each period one agent is allowed to revise his/her linking strategy. In doing so, agents seek to improve their discounted future payoff stream, while considering the effect of their actions in the current period on the actions of others in the future. Agents take into account that the links they form or sever may influence both hoe trade takes places at future dates as well as the decision of other agents on how to form links. Therefore, their linking strategies depends on their trading strategy. More precisely, I consider that agents revise their links given that they follow the trading strategy profile $\sigma^{*}$ described above. In this case, agents' discounted future payoff stream on the equilibrium path of trading without collateral is given by (10) and (11), respectively.

I ask questions related to stable outcomes and convergence of this dynamic network formation process. I aim to identify networks that may be absorbing (in the sense that the process, once there, remains there), and show that they attract the process at least from some initial conditions. More precisely, a network is absorbing if there is no agent that can improve his/her discounted future payoff stream when he/she has the possibility to change his/her current relationships and anticipates the consequences of this choice on 
other agents actions. The notion of convergence is more encompassing as it captures the agents' incentives to change their relationships such that their choices generates a sequence of networks converging to an absorbing network in finite time.

The network formation process takes place as follows. At the beginning of each period $t$, agents observe the network $g^{t-1}$ that has emerged the previous period. The network $g^{t-1}$ reveals information only about the number of intermediaries between any pair of traders at date $(t-1)$. One agent $k$ is selected and endowed with the capacity to unilaterally sever existing links with any other agents and/or propose one link to another agent if the link does not exist to begin with. The agent that has been proposed a link can accept or reject. These actions create a new network, $g^{t}$. In the new network, each agent observes the history of each of his neighbors up to time $t$. Agents are then matched to trade and trading takes places through the network as described in Section 3.2. That is, agents decide whether to trade without or against collateral. Transactions take place accordingly. At the end of the period, each agent $j$ with an investment opportunity makes a payment $f_{j}^{t}$ and possibly pays fees to the intermediaries. The current period then ends, and the whole process begins again ad infinitum.

To formalize these ideas I formulate a dynamic game of network formation, and study which networks emerge on the equilibrium path of this game. For this, I assume that agents decisions to form links are governed by linking strategies that depend on the historically given network, $g^{t-1}$, and on the trading strategy, $\sigma^{*}$, that prescribes agents which contracts to trade. The linking strategy of an agent prescribe him/her a set of actions to take whenever he/she is endowed with the capacity to take decisions. Suppose that $k$ is the agent selected to take decisions at time $t$. Then his linking strategy $\mu_{k}\left(g^{t-1}, \sigma^{*}\right)$ prescribes a vector $\left(\mu_{k j_{1}}, \mu_{k j_{2}}, \ldots, \mu_{k j_{p}}\right)$ of revised linkages between $k$ and a subset of players $\left\{j_{1}, j_{2}, \ldots, j_{p}\right\}$, where $\mu_{k j_{l}} \in\{0,1\}$. When $\mu_{i j_{l}}=1$, it implies that $k$ proposes a link to $j_{l}$, and $\mu_{k j_{l}}=0$ implies that $k$ severs a link with $j_{l}$. Clearly, the strategy prescribes as well the choice of the subset of players $\left\{j_{1}, j_{2}, \ldots, j_{p}\right\}$, which can be any subset of $N$, including the empty set. For a player $j_{l}$ such that $\mu_{k j_{l}}=1$, the set of actions is $\mu_{j_{l}}\left(g^{t-1}, \sigma^{*}\right)=\{Y e s, N o\}$, depending on whether she accepts or rejects the link. A strategy profile precipitates, for each network $g^{t}$, some probability measure over the feasible set $F\left(g^{t}\right)$ of future networks 
starting from $g^{t}$.

The process of network formation creates values for each player. The overall payoff to any agent $k$ depends on both the linking strategy and the trading strategy that agents follow. Each agent needs to consider if there are any spillovers from his/her linking decisions on how trading takes place at future dates. For instance, on the equilibrium path of trading without collateral described in Proposition 2, the payoff of an agent $i$ with a liquidity surplus is given by (10), while the payoff of an agent $j$ with an investment opportunity is given by (11). However, when they revise their links, agents can form networks such that the number of intermediaries that facilitate some transactions becomes very large. If this the case, condition (7) can be violated and trading without collateral is no longer an equilibrium.

Definition 1 An equilibrium process of network formation is a linking strategy profile $\left(\mu_{1}, \mu_{2}, \ldots, \mu_{2 n}\right)^{*}$ with the property that no agent $k$ when given the opportunity to revise his/her linking strategy strictly benefits from departing from $\mu_{k}^{*}$, given that all traders (including him/herself) follow the trading strategy $\sigma^{*}$.

The equilibrium depends on how large the cost $\kappa$ of acquiring information is. If $\kappa=$ 0, then each agent can form costless links with all other agents in the economy. This allows them to trade every period directly with the counterparty set by the matching technology, without paying intermediation fees. All the implications from Section 3.1 follow immediately.

The interesting trade-off arises when $\kappa>0$. The following two propositions describe the equilibrium networks.

Proposition 3 Suppose that traders follow the trading strategy $\sigma^{*}$ and that the cost of accessing information is $\kappa>0$. Then there exists an equilibrium linking strategy such that a star network is an absorbing state of the dynamic network formation game if the opportunity cost of collateral is

$$
r-1 \geq \frac{1}{\delta(1-p)}(1+\gamma-\delta)
$$


Proof. A proof is provided in the appendix.

Condition (12) is the equivalent of (7) for a star network and insures that agents are better off trading without collateral through a central broker dealer, than trading against collateral anonymously, outside the network.

In a star network access to information is asymmetrically distributed: The agent in the centre has access to the complete history of financial transactions while periphery traders have very scarce information. The asymmetry reflects the two types of incentives that govern agents decisions when they form links. The first incentive is related to the rewards from intermediation: players would like to place themselves between others in order to acquire benefits from intermediation. The second incentive arises out of the desire to avoid sharing surpluses with intermediaries; in other words, individuals will try to circumvent intermediate players to retain more of the surplus for themselves. The equilibrium network is the result of the interplay between these two incentives. The first incentive pressures towards a star structure, while the second pressures towards an homogeneous, dense network. Proposition 3 shows that the first effect dominates the second when there are informational frictions. This effect is amplified by the fact that the agents with a liquidity surplus receive only their reservation value. There is an added layer of complexity when they have bargaining power, as discussed in Section 5.3.

The notion of equilibrium employed for the result in Proposition 3 implies that once traders are connected in an equilibrium network, no agent can revise her relationships and strictly profit from such deviation. Condition (12) ensures that trading without collateral is supported on the equilibrium path of the trading game when agents are connected in a star network and they follow trading strategy $\sigma^{*}$. However, I illustrate that there are no profitable deviations from the star network when agents are both on and off the equilibrium path of trading without collateral.

Assume first that we are on the equilibrium path of trading without collateral. Then, if traders are connected in a star network, each receives a continuation payoff given by (10) or $(11)^{3}$, depending on whether they have a liquidity surplus or an investment opportunity. Clearly, the central trader extracts substantial benefits from intermediating transactions

\footnotetext{
${ }^{3}$ Where $g^{t}$ is a star for any $t$.
} 
between other traders. Changing his/her linking strategy implies severing a link with a periphery trader. However, this move only reduces his/her intermediation rents. The periphery traders will not want to change their linking behavior either. Agents with a liquidity surplus are indifferent about their position in the network, since they do not pay nor gain intermediation fees. They are also indifferent whether they trade with or without collateral. Agents with an investment opportunity pay intermediation fees to at most one intermediary. Any change in their linking strategy induces losses. First, no trader finds it beneficial to exchange his relationship with the central trader and link with another periphery trader. The move will merely decrease his payoff as he has to pay fees to an additional intermediary. Second, no two periphery traders find it beneficial to form a link. If two spokes form a link, they need to pay the cost $\kappa$ every period until they are matched to trade. Since this happens with probability $\frac{1}{n}$, the link is too expensive to maintain for any potential benefits it may bring.

Consider next that at least some agents have deviated from the equilibrium path of trading without collateral. However, a star network is an equilibrium outcome as long as agents expect that all traders follow the trading strategy $\sigma^{*}$ after any history, either on or off the equilibrium path. The reason is that the trading strategy $\sigma^{*}$ discriminates only against traders that renege on payments without punishing the innocent ones. There are three situations to analyze in order to show that deviations from the equilibrium path of trading without collateral does not change traders' linking behavior. Suppose that $k$ is the periphery agent that is selected at date $t$ to revise his/her linking strategy. If $k$ has a liquidity surplus, she does not pay any intermediation fees. Thus she is indifferent where she is positioned in the network, as well as, whether she without or against collateral. If $k$ has an investment opportunity and has always made the due payments, he understands that the trading strategy that agents follow punishes only the defectors. Thus, his goal is to minimize intermediation fees, given that he expects to be trading without collateral at all future dates. If $k$ has an investment opportunity, but has reneged on payments in the past, he expects to be bound to trade against collateral thereafter. Since he does not pay intermediation fees in this case, he won't strictly benefit by changing his position in the network. 
To fully reveal the trade off that agents face between forming relationships in order to trade without collateral and accepting a lower share of the surplus, I study the convergence of the network formation process from some initial conditions. This will also indicate whether the star network is the only equilibrium outcome of the network formation process. I start by assuming that traders are connected in a network and aim to identify a linking strategy such that, if they all follow it, the outcome of their decisions drive the network formation process to a star-shaped network. Then I need to show that no trader has an incentive to deviate from her linking strategy. For tractability, I focus on the subclass of minimally connected networks. Such networks have the property that between any pair of players there exists a unique sequence of intermediaries. More importantly, in minimally connected networks every link is used in at least one transaction with probability close to 1. Such networks maximize aggregate welfare, as they support trading without collateral at the lowest linking cost. Therefore, I restrict the action space and allow the active player at state $s$ to make only one linking proposal, conditional on severing at least one link. ${ }^{4}$

Traders' linking actions induce a sequence of networks, such that each network in the sequence is obtained from the previous one by adding or severing links. I restrict the attention to consider only the addition and the severing of one link at a time. Formally, a sequence from network $g$ to network $g^{\prime}$ is a finite series of adjacent networks $g^{1}, g^{2}, \ldots, g^{t}$ with $g=g^{1}$ and $g^{\prime}=g^{t}$ such that at any step $\tau \in\{1,2, \ldots t-1\}$ the transition from $g^{\tau-1}$ to $g^{\tau}$ is given by $g^{\tau}=g^{\tau-1}-i_{\tau} k+i_{\tau} l$, where $\left(g_{\tau-1}-i_{\tau} k+i_{\tau} l\right)$ is the network $g^{\tau-1}$. When traders act in a predetermined order of play, the sequence of networks is deterministic. A sequence of networks is supported as an equilibrium of the network formation process if there exists a strategy profile $\boldsymbol{\mu}$ that supports the sequence of network and $\boldsymbol{\mu}$ is an equilibrium.

Proposition 4 If $\kappa>0$, then from any minimally connected network that connects all traders there exists a sequence of networks to a star-shaped network that is supported as an equilibrium of the network formation process.

Proof. The proof is provided in the appendix.

\footnotetext{
${ }^{4}$ Allowing traders to leave the network by severing links without forming a new link is straighforward. However, the result in Proposition 4 would require a condition similar to (12).
} 
This result shows that a star network is the unique equilibrium outcome, at least within the class of minimally connected networks. While there can exist multiple equilibrium strategies that support a star network, Proposition 4 insures that no other (minimally connected) networks are feasible as an equilibrium outcome. The reason is that we can always find a strategy that drives the dynamics of the network formation towards a star.

The intuition for this result is as follows. In a star network, the centre gains substantially larger benefits than other traders. This implies that some traders will compete to gain strategic positions that allow them to extract intermediation rents. However, these strategic motives are offset when agents are selected to revise their strategy in a certain sequence. Then, the incentives to acquire a larger share of the surplus dominate competition pressures and drive the number of intermediaries to one. Forward looking behavior enables traders to anticipate the consequences of their own actions. Hence, in any minimally connected network, for a deterministic sequence of agents, each agent can rely on her successors to drive the network formation process towards a star. Similar considerations as above, motivate why such a path exists even when some players might deviate from trading without collateral.

The order of play in which agents act matters for establishing who become the central counterparty. However, the initial size of a trader, quantified through the amount of intermediation rents she extracts, plays a role in whether she becomes the central counterparty. For instance, in many cases the trader with most links in the initial network becomes the centre of the star, while a periphery trader more likely remains peripheral. The rich get richer.

\section{Discussion}

\subsection{OTC Trading and Asset Properties}

The results in this paper are indicative about which kind of assets we should expect to be traded over the counter, relying on relationships. When there are informational frictions and $\kappa>0$, agents need to decide how much to spend on acquiring information. Their decision is driven by whether it is feasible without collateral. This in turn depends on the 
opportunity cost of collateral. If the opportunity cost of collateral is sufficiently high agents trade without collateral over the counter in dealer-centric markets. When the opportunity cost of collateral is sufficiently low, it follows from Corollary 1 that agents switch to trade against collateral. Since agents do not need access to the history of financial transactions when they trade against collateral, an additional implication arises from Corollary 1. That is, agents trade directly, every period, with the counterparty set by the matching technology. Such setting resembles more trading on an exchange, rather than over the counter. In exchanges, traders' orders are usually matched through an electronic trading algorithm, which does not allow traders to observe the identity of their counterparty.

When there are no informational frictions and $\kappa=0$, markets are perfectly transparent and agent trade in every period directly with the counterparty set by the matching technology. Inefficiencies can arise even in perfectly transparent markets. ${ }^{5}$ Agents fail to trade without collateral, which is welfare improving, if the opportunity cost of pledging collateral is sufficiently low.

In addition, Corollary 1 shows that agents' choice to trade with or without collateral can be traced back to the properties of the underlying asset. In particular, the lower the relative difference between the expected return of the asset and the opportunity cost of collateral, the more likely is that agents trade without collateral. When there are informational frictions, this implies that agents trade assets without collateral over the counter through a central broker-dealer. In contrast, as the relative difference increases, assets are traded in a setup similar to an exchange.

Another dimension that affects trading outcomes is market liquidity. In particular, inefficiencies are more likely to arise in illiquid markets, when $\delta$ is small, as agents find it more attractive to trade against collateral.

\subsection{One Central Counterparty}

The model I have proposed explains trade concentration in OTC markets based on two driving forces. First, counterparties have an incentive to interact repeatedly, as this allows

\footnotetext{
${ }^{5}$ Inefficiencies are more pronounced when there are informational frictions. As condition (12) shows, there is an efficiency loss as agents pay intermediation fees if they trade through a central broker-dealer.
} 
them to trade the first-best contract. Second, agents that facilitate transactions between other traders gain intermediation benefits. While we usually expect that OTC markets are dominated by a few central counterparties, rather than a single entity, this model stylizes the inequality in the distribution of trades in the markets.

The reason the model predicts one central counterparty is that traders' incentives to minimize the number of intermediaries are fully exploited. Consider for instance the case of an interlinked star network as in Figure 3. When an agent with an investment opportunity linked with centre $i$ is matched to trade with an agent with a liquidity surplus linked with centre $i^{\prime}$, he needs to pay intermediation fees to two intermediaries. If given the possibility, the agent linked with centre $i$ has then an incentive to switch and form a link with centre $i^{\prime}$. Given he is forward looking, he anticipates that all agents will subsequently revise their linking strategy in the same direction. Free-riding, in the sense of waiting for others to move first, is not appealing as traders incur an opportunity cost when they postpone revising their links.

Agents, thus, benefit more from trading through one central counterparty than through several. The underlying explanation is that the fee structure that intermediaries charge does not grant monopoly power to the central trader. While he/she gains substantial benefits, the capacity to extract rents from periphery traders does not increase with the number of trades intermediated. In these circumstances, trading through one central counterparty may become less attractive only when either the central or periphery traders face capacity constraints. If either the central trader or the spokes are constrained in the number of links they can have, this requires the emergence of a few central counterparties to intermediate all trade.

\subsection{Bargaining Power and Intermediation Fees}

The results in this paper are robust to the choice of the fee structure, as long as it depends on the number of intermediaries. The particular one implemented in the model can be microfounded through a bargaining procedure where agents decide how to divide the surplus from trading by making alternating offers. This also insures that the agent with a liquidity surplus need not resign to accept her reservation value. I describe below 
the procedure, and for simplicity I assume that agents bargain over one unit of surplus.

Suppose that $(i, j)$ is a pair matched to generate the surplus and the sequence $\left(i_{1}, i_{2}, \ldots, i_{k}\right)$ are the intermediaries that facilitate the transaction in this order. Agents negotiate how to split the surplus via successive bilateral bargaining sessions. More precisely, agents bargain in the following order: $\left(i_{k}, j\right),\left(i_{k-1}, i_{k}\right), \ldots,\left(i_{1}, i_{2}\right),\left(i, i_{1}\right)$ if $j$ is the agent with the investment opportunity in the pair $(i, j)$, and in reversed order $\left(i_{1}, i\right),\left(i_{2}, i_{1}\right), \ldots,\left(i_{k}, i_{k-1}\right)$, $\left(j, i_{k}\right)$ if if $i$ is the agent with the investment opportunity in the pair $(i, j)$. Suppose that $j$ is the agent with an investment opportunity.

In each bilateral bargaining session, two players negotiate a partial agreement via the alternating-proposal framework of Rubinstein (1982). In each session, one agent, the proposer, makes an offer that the other agent, the receiver, either accepts or rejects. A partial agreement specifies the share for the receiver to exit the game. After a partial agreement, the other agent continues to negotiate the remaining surplus in one subsequent session, when she becomes the receiver. In other words, an intermediary $i_{l}$ on the path between $(i, j)$ will bargain as a receiver with an agent $i_{l-1}$ before him on the path over the surplus she acquired as a proposer from the agent $i_{l+1}$ that follows him on the path. As above, the agent with the investment opportunity in the pair $(i, j)$ is also the receiver.

A full agreement is reached when all bargaining sessions end in a partial agreement. That is, a full agreements is reached after $(k+1)$ successful bargaining sessions. An outcome consists of $(k+1)$ partial agreements that specify player's $l$ share of the surplus, denoted as $x_{l} \in[0,1]$, for $l \in\left\{i, i_{1}, i_{2}, \ldots, i_{k}, j\right\}$ such that $\sum_{l} x_{l}=1$. All bargaining sessions take place within one period, for a given matching $\mathbf{m}^{t}$. However, delay in reaching an (partial) agreement is penalized. I assume that earnings are discounted at rate $\lambda$ depending on whether the agreement is reached sooner or later within one period. Clearly, the discount factor applied within one period need not be the same as the discount factor across periods.

The alternating-offers bargaining game has a unique subgame perfect equilibrium. When $i$ has a liquidity surplus and $j$ has an investment opportunity, then the shares players $\left(i, i_{1}, i_{2}, \ldots, i_{k}, j\right)$ receive at date $t$ are 
$\left(\frac{1}{(1+\lambda)^{d_{t}(i, j)+1}}, \frac{\lambda}{(1+\lambda)^{d_{t}\left(i_{1}, j\right)+2}}, \frac{\lambda}{(1+\lambda)^{d_{t}\left(i_{2}, j\right)+2}}, \ldots, \frac{\lambda}{(1+\lambda)^{d_{t}\left(i_{k}, j\right)+2}}, \frac{\lambda}{1+\lambda}\right)$ respectively. ${ }^{6}$ This bargaining procedure allocates to each intermediary a payoff that is a fraction of the surplus, decreasing with the distance between the intermediary and the agent with an investment opportunity.

Bargaining over the division of the surplus adds one layer of complexity in the decision of agents of how to form links. When the agent with a liquidity surplus receives more than her reservation value, she also has an incentive to avoid sharing the surplus with intermediaries. This implies each agent with a liquidity surplus is interested in maintaining direct relationships with each agent with an investment opportunity to save on intermediation fees. If the population is not too large, agents find that acquiring information is marginally less expensive than paying intermediation fees. The equilibrium network approaches perfect market transparency. In contrast, when the population is large, maintaining relationships with many agents becomes too costly. Agents prefer trading through one central broker-dealer.

\section{Conclusions}

I study a setting when trading risky assets over the counter requires collateral. Since collateral is costly, unsecured trading is desirable. Agents can trade against no collateral if they can condition current and future terms of trade on the information they have about past transactions. If there are no informational frictions, markets are perfectly transparent. Inefficiencies arise when markets are illiquid and/or the collateral is relatively valuable compared to the expected return of the asset. If there are informational frictions, agents rely on a network of relationships to trade against no collateral. In particular they choose to trade through one central broker-dealer. Inefficiencies are more pronounced as agents have to pay intermediation fees to the central counterparty.

The results of this paper stylize features of over-the-counter markets: links are concentrated around a few players, and larger, richer players become central in the network.

\footnotetext{
${ }^{6}$ The complete derivations can be provided upon request.
} 


\section{References}

Acharya, V., and L. Pedersen, 2005, Asset Pricing with Liquidity Risk, Journal of Financial Economics 77, 375-410.

Afonso, G., A. Kovner, and A. Schoar, 2011, The Importance of Trading Relationships in the Fed Funds Market, working paper Fed New-York.

Allen, F., and A. Babus, 2008, Networks in Finance, Working Paper 08-07, Wharton Financial Institutions Center, University of Pennsylvania.

— , and E. Carletti, 2010, Financial connections and systemic risk, NBER Working Paper No. 16177.

Allen, F., and D. Gale, 1999, Innovations in Financial Services, Relationships, and Risk Sharing, Management Science 45, 1239-1253.

Bala, V., and S. Goyal, 2000, A Non-Cooperative Model of Network Formation, Econometrica $68,1181-1230$.

Bernhardt, D., V. Dvoracek, E. Hughson, and I. Werner, 2005, Why do large orders receive discounts on the London Stock Exchange?, Review of Financial Studies 18, 1343-1368.

Bloch, F., and M. Jackson, 2007, The Formation of Networks with Transfers Among Players, Journal of Economic Theory 133, 83-110.

Cocco, J., F. Gomes, and N. Martins, 2009, Lending Relationships in the Interbank Market, Journal of Financial Intermediation 18, 24-48.

Colla, P., and A. Mele, 2010, Information Linkages and Correlated Trading, Review of Financial Studies 23, 203-246.

D. Duffie, N. Garleanu, and L.H. Pedersen, 2007, Valuation in Over-the-Counter Markets, Review of Financial Studies 20, 1865-1900.

Duffie, D., N. Garleanu, and L.H. Pedersen, 2005, Over-the-Counter Markets, Econometrica $73,1815-1847$. 
Dutta, B., S. Ghosal, and D. Ray, 2005, Farsighted Network Formation, Journal of Economic Theory 122, 143-164.

Fainmesser, I., 2011, Intermediation in (Un)observable Financial Networks, working paper Brown University.

Gale, D., and S. Kariv, 2007, Financial Networks, American Economic Review, Papers and Proceedings 97, 99-103.

Gofman, M., 2011, A Network-Based Analysis of Over-the-Counter Markets, working paper University of Wisconsin.

Goyal, S., and F. Vega-Rodondo, 2007, Structural Holes in Social Networks, Journal of Economic Theory 137, 460-492.

Greif, A., 1993, Contract Enforceability and Economic Institutions in Early Trade: The Maghribi Traders' Coalition, American Economic Review 83, 525-548.

Jackson, M., and A. Wolinsky, 1996, A Strategic Model of Social and Economic Networks, Journal of Economic Theory 71, 44-74.

Kandori, M., 1992, Social Norms and Community Enforcement, Review of Economic Studies 59, 63-80.

Kiyotaki, N., and J. Moore, 1997, Credit Cycles, Journal of Political Economy 105, 211248.

Klein, D., 1992, Promise Keeping in the Great Society: A Model of Credit Information Sharing, Economics and Politics 4, 117-136.

Kletzer, K., and B. Wright, 2000, Sovereign Debt As Intertemporal Barter, American Economic Review 90, 621-639.

Leitner, Y., 2005, Financial Networks: Contagion, Commitment, and Private Sector Bailouts, Journal of Finance 60, 2925-2953.

Levin, J., 2003, Relational Incentive Contracts, American Economic Review 93, 835-857. 
Li, D., and N. Schurhoff, 2011, Dealer Networks, mimeo, University of Lausanne.

Mailath, G., and L. Samuelson, 2006, Repeated Games and Reputations (Oxford University Press).

Ozsoylev, H., and J. Walden, 2009, Asset Pricing in Large Information Networks, working paper UC Berkeley.

Tirole, J., 1996, Theory of collective reputations, Review of Economic Studies 63, 1-22.

Upper, C., and A. Worms, 2004, Estimating Bilateral Exposures in the German Interbank Market: Is There a Danger of Contagion?, European Economic Review 48, 827-849.

Zawadowski, A., 2010, Entangled Financial Systems, working paper Princeton University. 


\section{Appendix}

Proof of Proposition 1. I show that there exists a trading strategy profile that is a subgame perfect equilibrium of the repeated random matching game with perfect information. The trading strategy of an agent $i$ with a liquidity surplus depends on the reputation of the agent $j$ with an investment opportunity with whom she is matched at a given date $t>1$. Thus, her strategy prescribes she trades without collateral unless he has repaid $f_{j}^{\tau}=0$ at least one date $\tau<t$ in the past. The trading strategy of an agent $j$ with an investment opportunity depends on whether he trades without or against collateral at a given date $t$. When trading without collateral, his strategy prescribes that he repays $f_{j}^{t}=1$ at the end of the period. Otherwise, if he is required to pledge collateral, his

strategy prescribes that he repays $f_{j}^{t}=1$ when $\theta_{j}^{t}=R$ and $f_{j}^{t}=0$ when $\theta_{j}^{t}=0$ at the end of the period. However, if he repaid $f_{j}^{\tau}=0$ at least one date $\tau$ in the past, he will repay 0 thereafter in all periods when he trades without collateral. This implies that an agent that has reneged on a payment in a period when trading without collateral, he will renege on payments thereafter.

This strategy profile is a subgame perfect equilibrium if it is an equilibrium of the repeated game for any history $\mathbf{h}^{t}$, including those histories that are reached out of equilibrium.

Consider an agent, $i$, with a liquidity surplus and an agent, $j$, with an investment opportunity that meet at random at a given date $t$. First, take the agent, $i$, with a liquidity surplus. Her continuation payoff from trading without or against collateral is

$$
\sum_{\tau=1}^{\infty} \delta^{\tau} .
$$

Thus, she has no benefit from deviating from her strategy after any history. This includes histories off the equilibrium path when the agent with a liquidity surplus herself has failed to trade without collateral. Recall that her strategy is conditional only on the actions of the agent with an investment opportunity she has been matched to trade. Implicitly, her strategy prescribes that she returns to trade without collateral after any deviation when she traded against collateral. 
Then, consider the case of the agent, $j$, with an investment opportunity. Suppose we are on the equilibrium path of trading without collateral. At the end of the period he faces the choice of whether to repay 1 to the agent with a liquidity surplus, or retain the return of the asset for himself. If he makes the payment, he expects to trade without collateral thereafter, and his continuation payoff is

$$
\left(\theta_{j}^{t}+r-1\right)+\sum_{\tau=1}^{\infty} \delta^{\tau}(p R+r-1) .
$$

In contrast, at each date $t$ he doesn't make the payment, he expects to be punished to trade against collateral thereafter, and his continuation payoff is

$$
\left(\theta_{j}^{t}+r\right)+\sum_{\tau=1}^{\infty} \delta^{\tau}[p(R+r-1)]
$$

Thus, he does not find the deviation profitable when

$$
\frac{\delta}{1-\delta}(r-1)-1 \geq \frac{\delta}{1-\delta} p(r-1)
$$

or

$$
r-1 \geq \frac{(1-\delta)}{\delta(1-p)}
$$

Consider now histories off the equilibrium path. There are three possibilities: the agent, $j$, with an investment opportunity has deviated in the past; the agent, $j$, with an investment opportunity had been required to pledge collateral in the past; and the agent, $i$, with a liquidity surplus has deviated in the past. In either case, it is not beneficial for the agent with an investment opportunity to deviate from his strategy.

First, if agent $j$ is a defector, agent $i$ requires him to pledge collateral at the beginning of the period. Then, his strategy prescribes that he repays $f_{j}^{t}=1$ when $\theta_{j}^{t}=R$ and $f_{j}^{t}=0$ when $\theta_{j}^{t}=0$ at the end of the period. He can only deviate by paying 0 in the good states of the world when $\theta_{j}^{t}=R$. However, this is not beneficial, as his continuation payoff from such a move is $\left\{R+\sum_{\tau=1}^{\infty} \delta^{\tau}[p(R+r-1)]\right\}$. This is strictly smaller than the continuation he receives from following his strategy, $\left\{(R+r-1)+\sum_{\tau=1}^{\infty} \delta^{\tau}(p R+r-1)\right\}$. 
Second, suppose that agent $j$ has been required to pledge collateral in the past. If he repaid 0 , the agent $i$ requires him to pledge collateral again at date $t$. He can only deviate by paying 0 in the good states of the world when $\theta_{j}^{t}=R$. However, this is not beneficial, as his continuation payoff from such a move is $\left\{R+\sum_{\tau=1}^{\infty} \delta^{\tau}[p(R+r-1)]\right\}$. This is strictly smaller than the continuation he receives from following his strategy, $\left\{(R+r-1)+\sum_{\tau=1}^{\infty} \delta^{\tau}[p(R+r-1)]\right\}$. If he repaid 1 , he now trades without collateral and the same reasoning as for deviations from the equilibrium path applies.

Third, suppose the agent, $i$, with a liquidity surplus has deviated in the past. Her strategy prescribes that she returns to trade without collateral. The agent with an investment opportunity faces the same trade off as on the equilibrium path of trading without collateral. This concludes the proof.

Note: The sequential nature of the moves in each period allows the agent with the investment opportunity to observe the action of the agent with a liquidity surplus before he makes his choice.

Proof of Corollary 1. Suppose that trading against collateral is not the unique equilibrium. This implies that agents must trade without, at least at some dates. Let $q$ be the frequency with which agents trade without and $(1-q)$ the frequency with which agents trade against collateral.

On this equilibrium path, at the end of each period $t$ when trading without collateral, an agent, $j$, with an investment opportunity has a continuation payoff of

$$
\left(\theta_{j}^{t}+r-1\right)+\sum_{\tau=1}^{\infty} \delta^{\tau}\{q(p R+r-1)+(1-q)[p(R+r-1)]\} .
$$

In contrast, if he deviates from the equilibrium path, he expects to be punished to trade against collateral thereafter. His continuation payoff in this case is

$$
\left(\theta_{j}^{t}+r\right)+\sum_{\tau=1}^{\infty} \delta^{\tau}[p(R+r-1)]
$$


Since trading without collateral with $q$ frequency is an equilibrium it must be that

$$
-1+\sum_{\tau=1}^{\infty} \delta^{\tau} q(p R+r-1) \geq \sum_{\tau=1}^{\infty} \delta^{\tau} q[p(R+r-1)]
$$

or

$$
1 \leq \frac{\delta}{(1-\delta)} q(1-p)(r-1)
$$

which is a contradiction given that $(r-1)<\frac{1-\delta}{\delta(1-p)}$

Proof of Proposition 2. I show that the strategy profile $\sigma^{*}$ described in the text is a sequential equilibrium of repeated random matching trading game through the network. When agents are connected in a network, they repeatedly trade with their neighbors. This implies that is not necessary to spell out agents' beliefs, as the setting is equivalent with a standard repeated game of complete (local) information.

The strategy profile $\sigma^{*}$ is a subgame perfect equilibrium if it is an equilibrium of the repeated game for any history profile as described by the network $g$. This includes histories that can only be reached out of equilibrium. I show that this is the case for agents with a liquidity surplus, intermediaries, and agents with an investment opportunity. Let $(i, j)$ be the pair matched to trade and $\left(i_{1}, i_{2}, \ldots, i_{k}\right)$ be the sequence of intermediaries that facilitates the transaction.

First, consider an agent with a liquidity surplus. The same logic as in the proof of Proposition 1 applies. Since an agent with a liquidity surplus is indifferent between trading without or against (in each case, her continuation payoff being $\sum_{\tau=1}^{\infty} \delta^{\tau}$ ), she has no benefit from deviating from her strategy for any history she observes.

Second, consider the case of intermediaries. I show that strategy of the intermediary $i_{k}$ is an equilibrium. The case of the other intermediaries is then straightforward, since their strategy is to trade the contract required by $i_{k}$. Suppose we are on the equilibrium path of trading without collateral. The continuation payoff of $i_{k}$ is larger when he/she trades without collateral than against collateral

$$
\gamma+\sum_{\tau=1}^{\infty} \delta^{\tau} \sum_{\substack{(l, j) \in \mathbf{m}^{\tau} \\ i_{k} \in P_{\tau}(l, j)}} \frac{1}{n} \gamma^{d^{\tau}\left(i_{k}, j\right)+1} \geq 0
$$


where $\gamma+\sum_{\tau=1}^{\infty} \delta^{\tau} \frac{1}{n} \gamma^{d^{\tau}\left(i_{k}, j\right)+1}$ represent the expected marginal intermediation benefit he/she receives from facilitating trade between $j$ and his counterparty, $l$, at each date $\tau$. As for the histories off the equilibrium path, the non-trivial case is to check whether the intermediary has an incentive to punish the agent $j$ with the investment opportunity when he has reneged on payments in the past. If this is the case, the strategy of an intermediary prescribes him/her to trade against collateral. The marginal continuation payoff from facilitating trade for $j$ is 0 . Deviating from this strategy and trading without collateral yields the same continuation payoff for the intermediary. I assume that this indifference settles the decision of the intermediary in the favor of the agent with the liquidity surplus.

Third, consider the case of an agent with an investment opportunity. Suppose we are on the equilibrium path of trading without collateral. At the end of each period when trading without collateral he faces the choice of whether to make the payment $\frac{1}{p}$ and pay intermediation fees, or renege. If he makes the payment, he expects to trade without collateral thereafter. His continuation payoff is

$$
\left[\theta_{j}^{t}+r-\left(\frac{1-\gamma^{d^{t}(j, k)+1}}{1-\gamma}\right)\right]+\sum_{\substack{\left(l, l^{\prime}\right) \in \mathbf{m}^{t} \\ j \in P_{t}\left(l, l^{\prime}\right)}} \gamma^{d^{t}\left(j, l^{\prime}\right)+1} f_{l^{\prime}}^{t}+\sum_{\tau=1}^{\infty} \delta^{\tau} \pi_{j \in \mathcal{I}}^{U}(g),
$$

where $\left(\frac{1-\gamma^{d^{t}(j, k)+1}}{1-\gamma}\right)$ represents the total payment he needs to make if the counterparty,

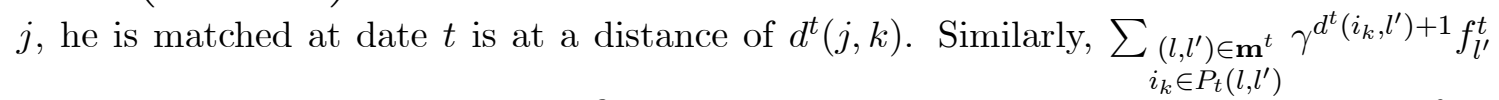
represents the intermediation benefits he receives at the current date $t$. In contrast, if he doesn't make the payment he expects to be punished to trade against collateral thereafter. His continuation payoff in this case is

$$
\left[\theta_{j}^{t}+r\right]+\sum_{\substack{\left(l, l^{\prime}\right) \in \mathbf{m}^{t} \\ j \in P_{t}\left(l, l^{\prime}\right)}} \gamma^{d^{t}\left(j, l^{\prime}\right)+1} f_{l^{\prime}}^{t}+\sum_{\tau=1}^{\infty} \delta^{\tau}\left\{p(R+r-1)+\sum_{\substack{\left(l, l^{\prime}\right) \in \mathbf{m}^{\tau} \\ j \in P_{\tau}\left(l, l^{\prime}\right)}} \frac{1}{n} \gamma^{d^{\tau}\left(j, l^{\prime}\right)+1}\right\}
$$

since he expects to receive benefits from intermediation even if trading against collateral 
on his behalf. Thus, he does not find the deviation profitable when

$$
\left(\frac{1-\gamma^{d^{t}(j, k)+1}}{1-\gamma}\right) \leq \sum_{\tau=1}^{\infty} \delta^{\tau} \sum_{k} \frac{1}{n}\left(-\frac{1-\gamma^{d^{\tau}(j, k)+1}}{1-\gamma}\right)+\frac{\delta}{1-\delta}(1-p)(r-1)
$$

Since $\sum_{k} \frac{1}{n} \frac{1-\gamma^{d^{\tau}(j, k)+1}}{1-\gamma} \leq \frac{1-\gamma^{\bar{d}+1}}{1-\gamma}$, condition (7) becomes sufficient for the strategy $\sigma^{*}$ to be a subgame perfect equilibrium. For the histories off the equilibrium path, the same logic as in the proof of Proposition 1 applies. This concludes the proof.

Note: Under the strategy profile $\sigma^{*}$, intermediaries that deviate and trade without collateral with agents with an investment opportunity that have reneged on payments in the past are not punished. However, this is not necessary. The fact that they are indifferent between trading without or against collateral with agents that defected, insures that their strategy is a subgame perfect equilibrium.

Proof of Proposition 3. I show that once the process of network formation reaches a star, it remains there, both on and off the equilibrium path of trading without collateral.

I start by considering we are on the equilibrium path of trading without collateral. The proof requires two steps. First, I define a strategy that keeps players connected in a star network. Second, I show that the strategy is an equilibrium.

Step 1.

For any trader $k$, let $\beta_{k}\left(g^{t}\right)=\sum_{k^{\prime} \in \mathcal{L}} \frac{1}{n} \frac{\gamma-\gamma^{d^{t}\left(k, k^{\prime}\right)+1}}{1-\gamma}$. If $k$ has an investment opportunity, $\beta_{k}\left(g^{t}\right)$ represents the amount of intermediation fees he expects to pay in the network $g^{t}$. If $k$ has a liquidity surplus, $\beta_{k}\left(g^{t}\right)$ does not enter in her payoff function and represents no more than a convenient decision rule for $k$.

I define a linking strategy $\boldsymbol{\mu}$ profile as follows. Suppose that trader $k$ is selected to make a decision at time $t$. Then $k$ exchanges one link from a neighbor $j\left(j k \in g^{t-1}\right)$ for a link with trader $i\left(i k \notin g^{t-1}\right)$ to minimize $\beta_{k}\left(g^{t-1}+k i-k j\right)$, if $\beta_{k}\left(g^{t-1}+k i-k j\right) \leq \beta_{k}\left(g^{t-1}\right)$. Otherwise she/he does not change her links. In addition, agent $i$ accepts the link, if proposed.

If all traders follow the strategy profile $\boldsymbol{\mu}$, a star network $g^{*}$ is absorbing. The reason is that trading through the central counterparty, which I label $\ell^{*}$, minimizes $\beta_{k}\left(g^{t}\right)$ for all $k$. Since all traders are connected to the central trader, it follows that under the linking 
strategy $\boldsymbol{\mu}$, a star network is absorbing.

Step 2.

Next, I show that the linking strategy profile $\boldsymbol{\mu}$ is an equilibrium of the extensive network formation game, given that agents follow the trading strategy $\sigma^{*}$. This implies that neither an agent with a liquidity surplus, nor an agent with an investment opportunity can benefit from deviating from $\boldsymbol{\mu}$. Their incentives to deviate depend on whether they located at the periphery of the network or at the centre.

I study first periphery traders. An agent with a liquidity surplus does not pay intermediation fees. She is indifferent where she is in the network, as long as she does not need to pay linking costs. Hence, she has no incentive to deviate from the strategy described above.

An agent with an investment opportunity does not have an incentive to deviate from $\boldsymbol{\mu}$ when the following three conditions hold.

(i) No periphery agent $j$ with an investment opportunity exchanges the link to the central player $\ell^{*}$ for a link to another periphery $k$ in a star network $g$.

This holds because a periphery trader will receive following such deviation at most

$$
V_{j}\left(g^{*}+j k-j \ell^{*}, \sigma^{*}\right)=\pi_{j \in \mathcal{I}}^{U}\left(g^{*}+j k-j \ell^{*}\right)+\sum_{\tau=1} \delta^{\tau} \pi_{j \in \mathcal{I}}^{U}\left(g^{*}\right)
$$

as the trader returns to the strategy prescribed by $\boldsymbol{\mu}$ whenever given the chance. At the same time, the payoff of a periphery trader from staying in a star is

$$
V_{j}\left(g^{*}, \sigma^{*}\right)=\pi_{j \in \mathcal{I}}^{U}\left(g^{*}\right)+\sum_{\tau=1} \delta^{\tau} \pi_{j \in \mathcal{I}}^{U}\left(g^{*}\right)
$$

Substituting from eq. (9) and given that $\frac{1}{n} \frac{\gamma^{2}}{1-\gamma}+\frac{n-1}{n} \frac{\gamma^{3}}{1-\gamma}<\frac{1}{n} \frac{\gamma}{1-\gamma}+\frac{n-1}{n} \frac{\gamma^{2}}{1-\gamma}$, it follows that $V_{j}\left(g^{*}+j k-j i^{*}, \sigma^{*}\right)<V_{j}\left(g^{*}, \sigma^{*}\right)$.

(ii) No periphery player severs the link with the central player.

If a node is disconnected from the network, he engages in trade with the counterparty selected by the matching technology. However, trading aside of the network is as if 
interactions are one shot. Consequently, he will be trading against collateral and his payoff will be at most

$$
V_{j}\left(g^{*}-j \ell^{*}, \sigma^{*}\right)=\pi_{j \in \mathcal{I}}^{C}+\sum_{\tau=1} \delta^{\tau} \pi_{j \in \mathcal{I}}^{U}\left(g^{*}\right)
$$

since the trader will seek to link to the central counterparty as soon as it is its turn to move. From condition (12), we have that $\pi_{j \in \mathcal{I}}^{U}\left(g^{*}\right)>\pi_{j \in \mathcal{I}}^{C}$. It follows then that $V_{j}\left(g^{*}-j \ell^{*}, \sigma^{*}\right)<V_{j}\left(g^{*}, \sigma^{*}\right)$, and no player wants to be disconnected.

(iii) No two periphery players have an incentive to create form a new link.

The benefit a periphery trader extracts from creating a link with another periphery trader is given by

$$
V_{j}\left(g^{*}+i j, \sigma^{*}\right)=\frac{1}{n}(p R+r-1)+\frac{1}{n}(p R+r-1)+\frac{n-2}{n}[p R+r-1-\gamma]-\kappa+\sum_{\tau=1} \delta^{\tau} \pi_{j \in \mathcal{I}}^{U}\left(g^{*}\right)
$$

where I took into account that he is matched with the central node with probability $\frac{1}{n}$ and with the other periphery trader with probability $\frac{1}{n}$. This implies that he has to pay the cost $\kappa$ for being linked with the central trader with probability $\frac{1}{n}$ and for being linked with the other periphery trader with probability $\frac{n-1}{n}$. Thus, the deviation is not profitable for an agent with an investment opportunity as long as

$$
\kappa>\frac{1}{n} \gamma
$$

Note that the cost $\kappa$ need not be high when the population of traders is large. An agent with a liquidity surplus does not find beneficial to form a link with another periphery trader for any $\kappa>0$. The condition for the agent with a liquidity surplus implies the condition for the agent with a liquidity surplus and is sufficient for the result.

Consider now the case of the central trader. The central player has no incentive to sever a link with any periphery player. 
If the central trader receives in a star network intermediation benefits of

$$
\sum_{\tau=0} \delta^{\tau}\left(\frac{n-1}{n} \gamma\right)
$$

When central trader severs a link with a periphery trader, he/she receives from intermediation at most

$$
\frac{1}{n}\left(\frac{n-1}{n} \gamma\right)+\frac{n-1}{n}\left(\frac{n-2}{n} \gamma\right)+\sum_{\tau=1} \delta^{\tau}\left(\frac{n-1}{n} \gamma\right)
$$

where I took into account that he intermediates trade between $(n-1)$ pairs of agents only if he is matched to trade with disconnected player in the deviation period. Moreover, if the central trader has an investment opportunity, his trading benefits may be affected as well. As before, traders are assumed to return to the strategy prescribed by $\boldsymbol{\mu}$ as soon as given the possibility to move. Intermediation benefits are lower following a deviation, which prevents the central trader to sever a link.

To check whether a star network is an equilibrium off the path of trading without collateral we can follow Steps 1 and 2 above. The same procedure applies, taking into account how histories off the path of trading without collateral affect the continuation payoff of agents. There are three situation to analyze in order to show that deviations from the equilibrium path of trading without collateral does not change traders' linking behavior. Suppose that $k$ is the periphery agent that is selected at date $t$ to revise his/her linking strategy. If $k$ has a liquidity surplus, she does not pay any intermediation fees. Thus she is indifferent where she is positioned in the network, as well as, whether she trades without or against collateral. If $k$ has an investment opportunity and has always made the due payments, he understands that the trading strategy that agents follow punishes only the defectors. Thus, his goal is to minimize intermediation fees, given that he expects to be trading without collateral at all future dates. If $k$ has an investment opportunity, but has reneged on payments in the past, he expects to be bound to trade against collateral securities thereafter. Since he does not pay intermediation fees in this case, he is indifferent where he is positioned in the network. 
The derivations are straightforward.

Proof of Proposition 4.Let $\boldsymbol{\mu}$ be the strategy profile defined above.

I construct the following order of play. At a given date $t$, suppose that the network at the beginning of the period is $g^{t-1}$. Let $i^{t}$ be the trader selected to take actions at date $t$. Suppose that $i^{t}$ wants to change his/her position in network $g^{t-1}$, and let $\ell^{*}$ be the node for which $\beta_{i^{t}}\left(g^{t-1}+i^{t} \ell^{*}-i^{t} k\right)$ is minimized (assuming that $i^{t} k \in g^{t-1}$ ). Then, the trader selected to take actions at date $(t+1)$ is $i^{t+1} \in\left\{i \mid d^{t}\left(\ell^{*}, i ; g^{t}\right)=\max \right\}$, where $d^{t}\left(\ell^{*}, i ; g^{t}\right)$ is the number of intermediaries between $\ell^{*}$ and $i$ in the network $g^{t}$. In other words, the trader selected at date $(t+1)$ is the furthest away player from $\ell^{*}$ in the network $g^{t}$. This order of play selects recursively only periphery traders.

I show that if players follow the strategy profile $\boldsymbol{\mu}$ and act in the order of play defined above, then from any minimally connected network $g^{0}$ there exists a network path $g^{1}, g^{2}, \ldots, g^{t}$ to a star network and the strategy profile $\boldsymbol{\mu}$ is an equilibrium on the respective path.

We start at date 1. At the beginning of the period all traders are connected in the initial network $g^{0}$. Let $i^{1}$ be a randomly selected periphery trader to take actions. Suppose that $i^{1}$ exchanges one link from a neighbor $k^{1}\left(i^{1} k^{1} \in g^{0}\right)$ for a link to a trader $\ell^{*}\left(g^{0}\right)$ $\left(i^{1} \ell^{*}\left(g^{0}\right) \notin g^{0}\right)$ to minimize $\beta_{i^{1}}\left(g^{0}+i^{1} \ell^{*}\left(g^{0}\right)-i^{1} k^{1}\right)$. The new network at the end of date 1 is $g^{1}=g^{0}+i^{1} \ell^{*}\left(g^{0}\right)-i^{1} k^{1}$. At date 2, the trader $i^{2}$ that follows in the order of play exchanges one link from a neighbor $k^{2}\left(i^{2} k^{2} \in g^{1}\right)$ for a link with a trader $\ell^{*}\left(g^{1}\right)$ $\left(i^{2} \ell^{*}\left(g^{1}\right) \notin g^{1}\right)$ to minimize $\beta_{i^{2}}\left(g^{1}+i^{2} \ell^{*}\left(g^{1}\right)-i^{2} k^{2}\right)$. The new network at the end of date 1 is $g^{2}=g^{1}+i^{2} \ell^{*}\left(g^{1}\right)-i^{2} k^{2}$. The transition between any network $g_{\tau}$ to network $g_{\tau+1}$ takes place in the same way. If $\ell^{*}\left(g^{0}\right)=\ell^{*}\left(g^{1}\right)=\ldots=\ell^{*}\left(g^{\tau}\right)=\ell^{*}$, the strategy profile $\boldsymbol{\mu}$ is an equilibrium and the process converges to a star with trader $\ell^{*}$ in the center.

This can be shown by induction. I proof the first step: $\ell^{*}\left(g^{0}\right)=\ell^{*}\left(g^{1}\right)$. We know that for trader $i^{1}, \beta_{i^{1}}\left(g^{0}+i^{1} \ell^{*}\left(g^{0}\right)-i^{1} k^{1}\right)$ is minimum. Since $i^{2}$ is by construction of the order of play the furthest away from $\ell^{*}\left(g^{0}\right)$ in the network $g^{1}$, then $\beta_{i^{2}}\left(g^{1}+i^{2} \ell^{*}\left(g^{0}\right)-i^{2} k^{2}\right)$ is minimized as well. It follows that trader $i^{2}$ exchanges his link with $k^{2}$ for a link with $\ell^{*}\left(g^{0}\right)$. The same logic applies at every step $\tau$, which insures that $\ell^{*}\left(g^{\tau}\right)=\ell^{*}$ for any $\tau$. 


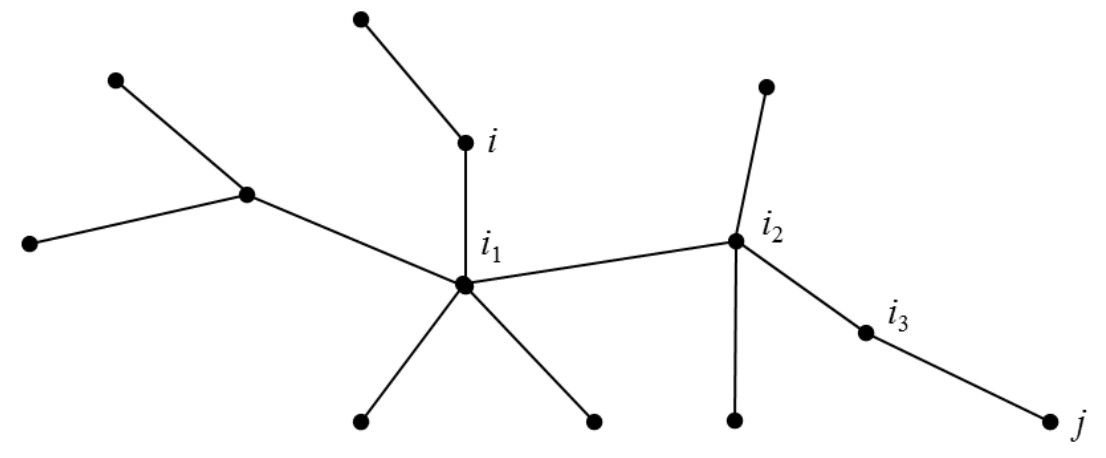

(a)

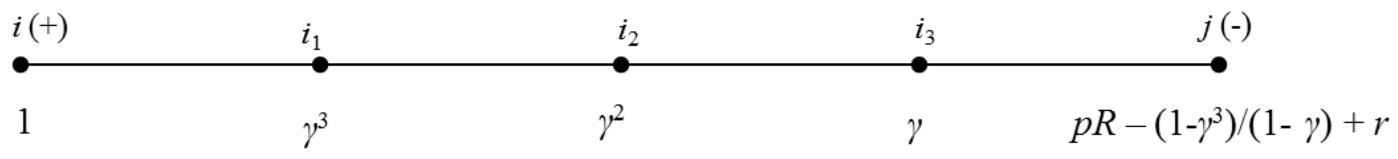

(b)

Figure 1: (a) The graph illustrates a network where a pair of agents $(i, j)$ have been matched to trade and the sequence of intermediaries $\left(i_{1}, i_{2}, i_{3}\right)$ that facilitates the trade. (b) The figure illustrates the payoffs that accrue to each party when $i$ and $j$ are matched to trade. 


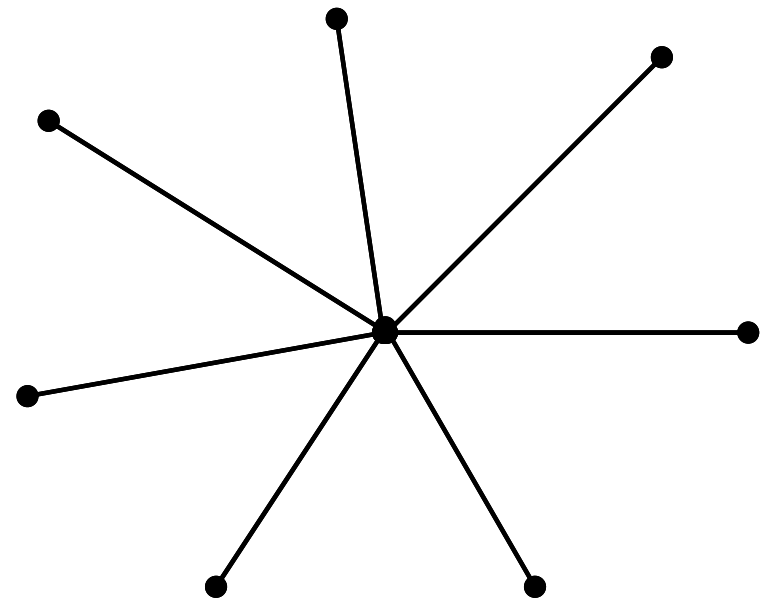

Figure 2: Star network architecture

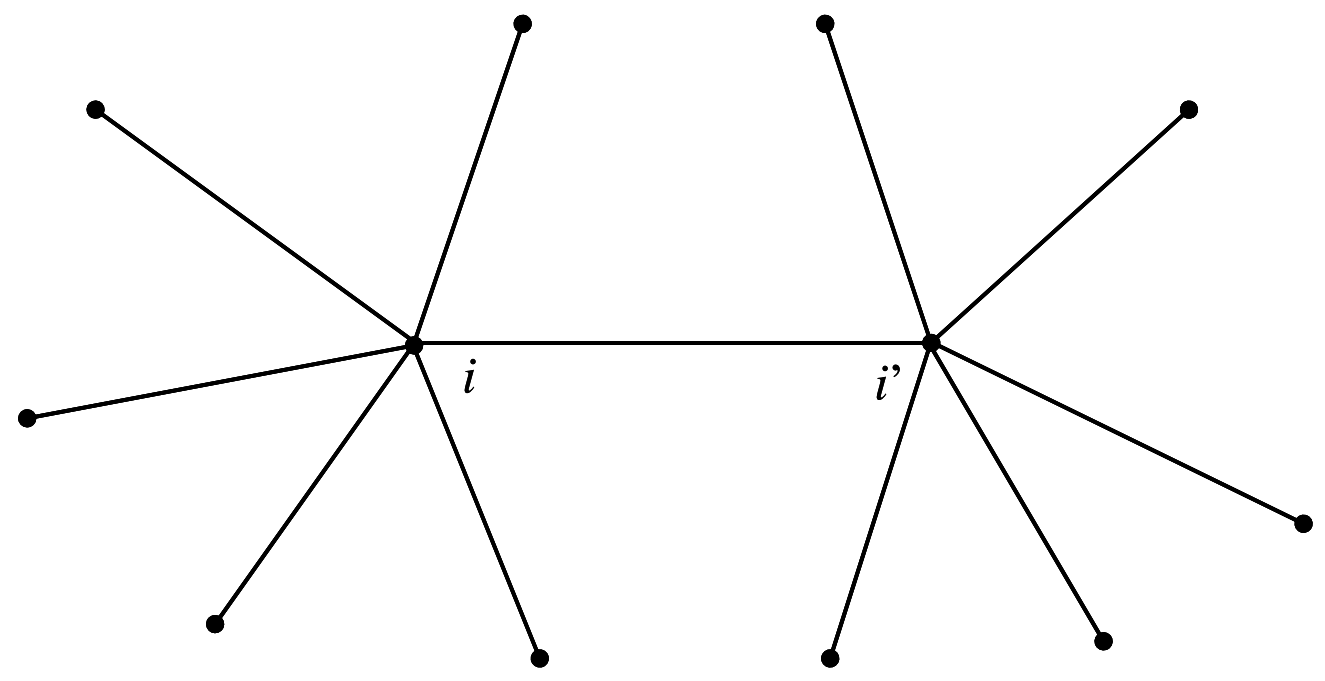

Figure 3: Interlinked star network architecture 